\title{
Musculoskeletal complaints among Italian X-ray technology students: a cross-sectional questionnaire survey
}

\author{
Antonio Lorusso*1, Luigi Vimercati² and Nicola L'Abbate'
}

\begin{abstract}
Background: There is a high prevalence of musculoskeletal disorders among healthcare professional students. Although recent studies show musculoskeletal disorders are a common problem among X-ray technologists, there are no data on these disorders among students of this healthcare profession. We have therefore estimated the prevalence of musculoskeletal complaints among a group of $\mathrm{X}$-ray technology students.

Methods: The students $(n=109)$ currently attending the 3-year X-ray technologist school at a large University in the Apulia region of Southern Italy were recruited for the study, with a 100\% participation rate. A questionnaire collected data concerning personal characteristics, physical exposure during training activities, and the presence of musculoskeletal symptoms in the neck, shoulders, low back, hand/wrist and legs.

Results: The prevalence of complaints in any body site over the previous 12 months was 37\%. Low back pain was the most frequently reported symptom (27\%), followed by neck (16\%), shoulder (11\%), leg (8\%) and hand/wrist (5\%) pain. Poor physical activity was associated with the complaints.

Conclusions: Our study showed prevalence rates of musculoskeletal complaints among X-ray technology students to be somewhat high, representing about half of those found in Italian technologists. The most common musculoskeletal problem was low back pain, which had also been found in research conducted among nursing students. Our research also showed a significant association between poor physical activity and the presence of musculoskeletal disorders in young university students.
\end{abstract}

\section{Background}

Musculoskeletal disorders (MSDs) are widespread in occurrence, with significant costs and impact on quality of life. Chronic musculoskeletal pain is reported by 1 in every 4 people in developed and underdeveloped countries $[1,2]$. Though the aetiology of MSDs in the general population is multifactorial, exposure to occupational risk factors make an important contribution to the occurrence of the disorders [3]. Between a quarter and a third of European workers report musculoskeletal pain, and young workers seem to be at greater risk than their older colleagues $[4,5]$. MSDs occur more frequently in certain occupations characterized by job tasks involving expo-

* Correspondence: a.lorusso@unifg.it

1 Department of Medical and Occupational Sciences, University of Foggia, Viale Pinto, 71100 Foggia, Italy

Full list of author information is available at the end of the article sure to physical risk factors, as found in some healthcare professions [3].

$\mathrm{X}$-ray technologists, also known as radiology technicians or radiographers, are trained health professionals responsible for performing diagnostic imaging procedures, providing an essential service in clinical healthcare. In Italy, $>21,000 \mathrm{X}$-ray technologists are employed in hospitals and radiology services, whose duties are in diagnostic imaging examination, including diagnostic radiography, computed tomography, magnetic resonance imaging, and mammography. In addition to X-ray technologists, others who conduct diagnostic imaging procedures include cardiovascular technologists and nuclear medicine technologists, while sonography is performed mainly by physicians. X-ray technologist tasks include preparing the patients for the radiologic examination, positioning and immobilizing them on examination table, 
positioning radiographic equipment over the appropriate area of patient's body, and developing X-ray films. Thus, work tasks performed by X-ray technologists frequently involve manual handling of patients and materials. Manual handling is an important risk factor in occupational musculoskeletal disorders of healthcare workers [6-8]; for example, a high prevalence of MSDs has been reported among nurses [6-10]. Similarly, recent studies have shown occupational MSDs to be a common problem among Xray technologists, with high prevalence rates for low back (60\% to $75 \%)$, neck ( $20 \%$ to $39 \%$ ) and shoulder $(21 \%$ to $28 \%$ ) problems [11-14].

Students of health professions frequently have to manual handle patients during their training activities and are at risk to MSDs just as the qualified healthcare professionals themselves. Nursing students, indeed, have high rates [15-19]. In addition, high prevalences of MSDs occur in other health professional student groups, such as medical, dental and occupational therapy students [2022].

However, to our knowledge, no data have been reported concerning MSDs among X-ray technology students, which was therefore the object of this study.

\section{Methods}

All the students $(n=109)$ currently attending the 3-year X-ray technologist school at a large University in the Apulia region of Southern Italy were recruited. The students of each year of the course were assembled by the director of the school for an appropriate lecture, set up for the survey. All accepted participation and signed the informed consent. Of these, 34 (31\%), 39 (36\%) and 36 (33\%) were attending the first, second and third years of the course, respectively. A questionnaire, used previously in a musculoskeletal survey among X-ray technologists [14], was distributed to the participants. Two first year students were absent when the questionnaire was issued, and attended the lecture set for the third year.

The questionnaire, given in detail in ref [14], collected information on individual characteristics, physical exposure during training and the presence of musculoskeletal complaints. Individual characteristics included gender, age, height/weight, smoking and leisure time physical activity. Questions on physical workload concerned the execution of physically demanding job tasks in the course of training on the hospital wards. In particular, students were asked whether they frequently undertook tasks such as patient lifting, transferring and positioning, portable equipment handling, lead-apron wearing, and cassette or other material handling. Musculoskeletal complaints in different body regions during the past 12 months were evaluated by questions derived from the Standardised Nordic Questionnaire, translated into Italian and vali- dated $[23,24]$. The body regions considered were neck, shoulders, low back, hand/wrist and legs.

Statistical associations between independent variables and symptoms in any body region were evaluated using the Student t-test for continuous variables and the chisquare test for categorical variables. Subsequently, all independent variables were included in a multivariate analysis. All analyses were conducted by means of Epi Info 3.3 software, with the level of significance being set at $\mathrm{p}<0.05$.

\section{Results and Discussion}

All 109 students completed the questionnaire and were included in the analysis. Of these, 60 (55\%) were males and 49 (45\%) females. Their mean age was 22.1 years (SD 3.4), and their mean body mass index was 23 (SD 2.7). Thirty students (27\%) were smokers and 55 (50\%) undertook regular physical activity ( $>3$ hours per week). As far as physical workload during training activities was concerned, all the students carried out the same tasks, rotating through the same hospital wards in each study year. This means that the physical exposure during training was similar for all the subjects. The prevalence of musculoskeletal complaints at any body site in the previous 12 months was $37 \%$. Low back pain (LBP) was the most commonly reported symptom (27\%), followed by neck (16\%) and shoulder pain (11\%). Table 1 shows the prevalence of the complaints with respect of the 3-year study course. Although neck, shoulder, hand/wrist and leg symptoms show a similar prevalence rate through the 3 years, low back symptoms gradually increase through the course. In Table 2 showing statistical analyses for musculoskeletal complaints at any body site, a significant association was found between poor physical activity and complaints. Multivariate analysis showed no statistical association between LBP and year of education.

To our knowledge, this is the first study to investigate musculoskeletal disorders among X-ray technology students. We estimated MSD prevalence rates among a complete group of students attending a 3-year university school. Prevalence of any MSD is lower in first-year students compared to the second-and third-year students. Furthermore, by specific body site, a difference was observed in LBP prevalence rates, with an increasing trend from the first to the last year. The difference in prevalence rates through the 3 years of the course was statistically not significant.

The results can be considered along with those of a previous investigation on Apulian X-ray technologists that used the same methodology [14], making for a direct comparison (Table 3). Musculoskeletal disorders can be seen to represent a significant concern for both X-ray technologists and students of this health profession. 
Table 1: Prevalence of musculoskeletal complaints with respect of the three years of the study course

\begin{tabular}{|c|c|c|c|c|c|c|c|c|}
\hline & \multicolumn{2}{|c|}{ Whole group } & \multicolumn{2}{|c|}{ First year } & \multicolumn{2}{|c|}{ Second year } & \multicolumn{2}{|c|}{ Third year } \\
\hline & $\mathbf{n}$ & $\%$ & $\mathbf{n}$ & $\%$ & $\mathbf{n}$ & $\%$ & $\mathbf{n}$ & $\%$ \\
\hline Any site & 40 & 37 & 9 & 26 & 18 & 46 & 13 & 36 \\
\hline Low back & 29 & 27 & 6 & 18 & 10 & 26 & 13 & 36 \\
\hline Neck & 18 & 16 & 5 & 15 & 6 & 15 & 7 & 19 \\
\hline Shoulder & 12 & 11 & 3 & 9 & 5 & 13 & 4 & 11 \\
\hline Legs & 9 & 8 & 3 & 9 & 4 & 10 & 1 & 6 \\
\hline $\begin{array}{l}\text { Hand/ } \\
\text { wrist }\end{array}$ & 6 & 5 & 1 & 3 & 3 & 8 & 2 & 6 \\
\hline
\end{tabular}

However, prevalence rates found among students are about half of those found in established technologists, but low back pain seems to be the most common musculoskeletal problem for both.

Our study shows that X-ray technology students are affected by MSDs in the same way as other health professional trainee groups, such as nursing, medical, dental and occupational therapist students [15-22]. Among them, nursing and X-ray technology students are the 2 groups that report very similar physical exposure, mainly related to manual handling of patients. For this reason, a comparison of MSD prevalence rates between these 2 groups was deemed appropriate. Prevalence of any MSD found in X-ray technology students is similar to that found in nursing students surveys carried out in Japan [15], but lower than in China [16], Australia [17] and Korea [18]. In particular, low back pain prevalence is higher than reported in Japan [15], but lower than in Australia and Korea $[18,19]$.

Poor physical activity and complaints at any body site were statistically significantly associated, according to the findings of previous data on nursing students [18]. No other associations between MSDs and individual variables were detected in the present study. However, these results should be interpreted with caution, since the small size of the study sample was inadequate to draw statistically significant conclusions. We preferred, however, to recruit students from only one University. This ensures that all the participants performed the same kind of training activities, and consequently reported a uniform physical exposure. Indeed, each Italian University has its own program of training activities, which may be different in duration and job tasks performed by the students. The difference among Universities could have represented a confounder in our case.

\section{Conclusions}

Overall, our study shows prevalence rates of MSDs among X-ray technology students to be somewhat high, representing about half of those found in technologists. The most common musculoskeletal problem is low back pain, in agreement with MSD research conducted among nursing students. Our research also shows a significant association between poor physical activity and the pres-

Table 2: Associations between complaints at any body site and individual characteristics.

\begin{tabular}{|c|c|c|c|c|c|c|}
\hline & & \multicolumn{2}{|c|}{ Any MSD } & \multicolumn{2}{|c|}{ No symptoms } & \multirow[t]{2}{*}{ p Value } \\
\hline & & $\mathbf{n}$ & $\%$ & $\mathbf{n}$ & $\%$ & \\
\hline \multirow[t]{2}{*}{ Gender } & men & 21 & 52.5 & 39 & 56.5 & 0.684 \\
\hline & women & 19 & 47.5 & 30 & 43.5 & \\
\hline \multicolumn{2}{|l|}{ Smoking } & 9 & 22.5 & 21 & 30 & 0.371 \\
\hline \multicolumn{2}{|c|}{ Regular physical activity } & 15 & 37 & 40 & 58 & 0.039 \\
\hline \multicolumn{2}{|c|}{ Age; years (mean, SD) } & \multicolumn{2}{|c|}{$22.6 \pm 4.0$} & \multicolumn{2}{|c|}{$21.9 \pm 3.0$} & 0.302 \\
\hline \multicolumn{2}{|c|}{$\mathrm{BMl} ; \mathrm{Kg} / \mathrm{m}^{2}$ (mean, SD) } & \multicolumn{2}{|c|}{$22.6 \pm 2.6$} & \multicolumn{2}{|c|}{$23.2 \pm 2.8$} & 0.271 \\
\hline
\end{tabular}

SD, Standard Deviation 
Table 3: Prevalence rates of musculoskeletal complaints found in Apulian X-ray technology students and X-ray technologists

\begin{tabular}{|c|c|c|c|c|}
\hline & \multicolumn{2}{|c|}{$\begin{array}{l}\text { X-ray technology students } \\
\qquad(\mathrm{N}=109)\end{array}$} & \multicolumn{2}{|c|}{$\begin{array}{l}\text { X-ray technologists } \\
(N=203)\end{array}$} \\
\hline & $n$ & $\%$ & $\mathbf{n}$ & $\%$ \\
\hline Any site & 40 & 37 & 136 & 67 \\
\hline Low back & 29 & 27 & 121 & 60 \\
\hline Neck & 18 & 16 & 40 & 20 \\
\hline Shoulder & 12 & 11 & 43 & 21 \\
\hline Legs & 9 & 8 & 28 & 14 \\
\hline Hand/wrist & 6 & 5 & 25 & 12 \\
\hline
\end{tabular}

ence of musculoskeletal disorders in young university students.

\section{Competing interests}

The authors declare that they have no competing interests.

\section{Authors' contributions}

AL contributed to conception and design of the study, performed statistica analysis and wrote the draft of the manuscript; LV collected and interpreted the data and wrote the draft of the manuscript; NL contributed to design of the study and revised critically the manuscript. All the authors read and approved the final version of the manuscript to be published.

\section{Acknowledgements}

The authors would like to thank Prof. Giuseppe Rubini, Director of X-ray technologist school at University of Bari, for his kind assistance in conducting this survey and all the students participating to this study.

\section{Author Details}

'Department of Medical and Occupational Sciences, University of Foggia, Viale Pinto, 71100 Foggia, Italy and ${ }^{2}$ Department of Internal Medicine and Public Medicine, University of Bari, Piazza Giulio Cesare 11, 70124 Bari, Italy

Received: 3 December 2009 Accepted: 24 April 2010

Published: 24 April 2010

\section{References}

1. Woolf AD, Akesson K: Understanding the burden of musculoskeletal conditions. The burden is huge and not reflected in national health priorities. BMJ 2001, 322:1079-80

2. Salaffi F, De Angelis R, Grassi W, MArche Pain Prevalence INvestigation Group (MAPPING) study: Prevalence of musculoskeletal conditions in an Italian population sample: results of a regional community-based study. I. The MAPPING study. Clin Exp Rheumatol 2005, 23:819-28.

3. Punnett L, Wegman DH: Work-related musculoskeletal disorders: the epidemiologic evidence and the debate. J Electromyogr Kinesiol 2004, 14:13-23.

4. The Work Foundation: Fit For Work? Musculoskeletal Disorders in the European Workforce. London 2009.

5. European Agency for Safety and Health at Work: Preventing risks to young workers: policy, programmes and workplace practices. Bilbao 2009.

6. Smedley J, Egger P, Cooper C, Coggon D: Manual handling activities and risk of low back pain in nurses. Occup Environ Med 1995, 52:160-3.

7. Lagerström M, Wenemark M, Hagberg M, Wigaeus Hjelm E: Occupational and individual factors related to musculoskeletal symptoms in five body regions among Swedish nursing personnel. Int Arch Occup Environ Health 1995, 68:27-35.

8. Lorusso A, Bruno S, L'Abbate N: A review of low back pain and musculoskeletal disorders among Italian nursing personnel. Ind Health 2007, 45:637-44
9. Engels JA, Gulden JW van der, Senden TF, van't Hof B: Work related risk factors for musculoskeletal complaints in the nursing profession: results of a questionnaire survey. Occup Environ Med 1996, 53:636-41.

10. Josephson M, Lagerström M, Hagberg M, Wigaeus Hjelm E: Musculoskeletal symptoms and job strain among nursing personnel: a study over a three year period. Occup Environ Med 1997, 54:681-5.

11. Bos E, Krol B, Star $L$ van der, Groothoff J: Risk factors and musculoskeletal complaints in non-specialized nurses, IC nurses, operation room nurses, and X-ray technologists. Int Arch Occup Environ Health 2007, 80:198-206

12. Kumar S, Moro L, Narayan Y: Perceived physical stress at work and musculoskeletal discomfort in X-ray technologists. Ergonomics 2004, 47:189-201.

13. Kumar S, Moro L, Narayan Y: Morbidity among X-ray technologists. Int J Ind Ergon 2004, 33:29-40.

14. Lorusso A, Bruno S, L'Abbate N: Musculoskeletal complaints among Italian X-ray technologists. Ind Health 2007, 45:705-8.

15. Smith DR, Sato M, Miyajima T, Mizutani T, Yamagata Z: Musculoskeletal disorders self-reported by female nursing students in central Japan: a complete cross-sectional survey. Int J Nurs Stud 2003, 40:725-9.

16. Smith DR, Wei N, Zhang RX, Lian XH, Wang RS: Musculoskeletal disorders among Chinese nursing students. Ergonomics Australia 2004, 18:18-22.

17. Smith DR, Leggat PA: Musculoskeletal disorders among rural Australian nursing students. Aust J Rural Health 2004, 12:241-5.

18. Smith DR, Choe MA, Chae YR, Jeong JS, Jeon MY, An GJ: Musculoskeletal symptoms among Korean nursing students. Contemp Nurse 2005, 19:151-60.

19. Mitchell T, O'Sullivan PB, Burnett AF, Straker L, Rudd C: Low back pain characteristics from undergraduate student to working nurse in Australia: a cross-sectional survey. Int J Nurs Stud 2008, 45:1636-44.

20. Leggat PA, Smith DR, Clark MJ: Prevalence and correlates of low back pain among occupational therapy students in Northern Queensland. Can J Occup Ther 2008, 75:35-41.

21. Smith DR, Leggat PA: Prevalence and distribution of musculoskeletal complaints among Australian medical students. J Musculoskelet Pain 2007, 15:39-46.

22. Smith DR, Leggat PA, Walsh $\mathrm{L}$ : Workplace hazards among Australian dental students. Aust Dent J 2009, 54:186-8.

23. Kuorinka I, Jonsson B, Kilbom A, Vinterberg H, Biering-Sorensen F, Andersson G, Jorgensen K: Standardised Nordic questionnaires for the analysis of musculoskeletal symptoms. Appl Ergon 1987, 18:233-7.

24. Gobba F, Ghersi R, Martinelli S, Richeldi A, Clerici P, Grazioli P: Italian translation and validation of the Nordic IRSST standardized questionnaire for the analysis of musculoskeletal symptoms. Med Lav 2008, 99:424-43

doi: 10.1186/1756-0500-3-114

Cite this article as: Lorusso et al., Musculoskeletal complaints among Italian X-ray technology students: a cross-sectional questionnaire survey BMC Research Notes 2010, 3:114 